\title{
研究論文
}

\section{Measuring the Ratio of Epi-thermal to Thermal Neutron Densities Using Thick Gold Foils}

\author{
By Akira FURUHASHI,* Keishi MATSUMOTO** and Makoto ŌBU*
}

\begin{abstract}
Measurements have been made of the cadmium ratios of gold foils for thicknesses ranging from approximately $2 \mathrm{mg} / \mathrm{cm}^{2}$ to $80 \mathrm{mg} / \mathrm{cm}^{2}$. Foil thickness correction factors are presented both graphically and in tabular form, which would be valuable for the determination of the ratio of epi-thermal to thermal neutron denslties. Some discussions on the components of the correction factor are also included here. Measurements in the core of JRR-1 are presented and the total epi-thermal neutron density is determined to be 0.11 times the thermal one.
\end{abstract}

\section{INTRODUCTION}

The ratio of epi-thermal to thermal neutron densities can be determined by activating the foils, which have the resonance absorption peak in epi-thermal region, with and without the cadmium cover to separate the activities into the sub-cadmium and the epi-cadmium components. However, the ratio of sub-Cd to epi-Cd activities of thick foils is not sufficient to determine the ratio of epithermal to thermal neutron densities. Specific activities of irradiated thick foils are, for a number of reasons reduced to substatially lower value than that of an ideal infinitesimally thin foil. The reduction factor of activity is fairly a large quantity even in the case of a foil which is thin enough in the usual sense. Furthermore, with or without the cadmium cover, the factors are quite different. Therefore, in order to compute the ratio of neutron densities, more data are required than mere measurements of bare and cadmium covered activities of thick foils.

Greenfield $^{(1)}$ discussed on indium foils as resonance detector and determined the foil thickness correction factor through the cadmium ratio measurements. Gold is also of ten used as the detector for this purpose since it has many advantages as foils. Here, we determined the correction factor for gold foils by the same method and techniques as his. By measuring the activities and cadmium ratios of foils for a variety of thicknesses and extraporating the data to zero thickness, one can determine the correct activity ratio of ideal foil. Properly comparing the activities of actual thick foils with this ideal value, correction factors for foil thickness can be determined as universally applicable data.

To separate the reduction factor of activity into its components by physical considerations is interesting from an academic point of view. This report deals with some works of this kind. Some differences are observed between the beta self-absorption factors for sub-Cd and for epi-Cd activity in foils.

Neutron self-shielding factor for epi-Cd activity is also derived experimentally and found to be substantially different from the predic. tion of theory.

\section{METHOD}

Let $A(x), A_{\text {ed }}(x), A_{\text {sub }}(x)$, and $A_{\text {epl }}(x)$ be the total or bare, the cadmium covered, the sub-Cd and the epi-Cd specific activities, respectively, induced in a gold foil of thickness $x$. Then

$$
\begin{aligned}
& A(x)=A_{\mathrm{sub}}(x)+A_{\mathrm{epl}}(x) \\
& A_{\mathrm{ed}}(x)=X A_{\mathrm{sub}}(x)+\frac{1}{F} A_{\mathrm{epl}}(x)
\end{aligned}
$$

* 古橋晃, 大部䠞。Japan Atomic Energy Res. Inst. (日本原子力研究所)

** 松本圭司。 Engng. Lab., Ishikawajima Heavy Ind. Co., Ltd.（石川島重工業秼技訹研究所） 
where $X=$ fraction of sub-Cd neutrons transmitted by the cadmium cover and $1 / F=$ fraction of epi-Cd neutrons transmitted by the cadmium cover. These fractions are taken to be independent of the thickness of gold and nearly equal to 0 and 1 , respectively.

The cadmium ratio is defined as

$$
R_{\mathrm{ed}}(x)=\frac{A(x)}{A_{\mathrm{ed}}(x)}
$$

Thus the sub-Cd and the epi-Cd components of the activities are separated according to the following formulae :

$$
\begin{aligned}
& A_{\mathrm{sub}}(x)=\left[1-\frac{F}{R_{\mathrm{ed}}(x)}\right] \frac{A(x)}{1-F X} \\
& A_{\mathrm{epi}}(x)=\left[\frac{F}{R_{\mathrm{cd}}(x)}-F X\right] \frac{A(x)}{1-F X}
\end{aligned}
$$

Define the activity reduction factors as

$$
\begin{aligned}
& f_{\mathrm{sub}}(x)=\frac{A_{\mathrm{sub}}(x)}{A_{\mathrm{sub}}(0)} \\
& f_{\mathrm{epi}}(x)=\frac{A_{\mathrm{ep} 1}(x)}{A_{\mathrm{epl}}(0)}
\end{aligned}
$$

$f_{\text {sub }}(x)$ and $f_{\text {epl }}(x)$ depend only on properties of gold and of the activity counter when the proper cadmium covers are used. Since all disturbing effects do not exist for $x=0$. as a matter of course, $f_{\text {sub }}(0)=f_{\text {epi }}(0)=1$.

Now the activity ratio of ideal foil is derived as follows;

$$
\begin{aligned}
\frac{A_{\mathrm{gub}}(0)}{A_{\mathrm{epi}}(0)} & =\frac{f_{\mathrm{epI}}(x)}{f_{\mathrm{fub}}(x)} \cdot \frac{A_{\mathrm{sub}}(x)}{A_{\mathrm{epl}}(x)} \\
& =\frac{f_{\mathrm{epi}}(x)}{f_{\mathrm{sub}}(x)} \cdot \frac{R_{\mathrm{cd}}(x) / F-1}{1-X R_{\mathrm{cd}}(x)}
\end{aligned}
$$

where the ratio of reduction factors $f_{\text {epl }}(x) /$ $f_{\text {sub }}(x)$ depends only on foil properties and does not depend on the flux ratio or on the activity counter.

Physical interpretation of the activity ratio of ideal foil thus derived has some ambiguity due to the character of integral measurement. The interpretation depends entirely on the spectrum type assumed for neutrons. Here we adopted the interpretation of Campbell's ${ }^{(2)}$. According to his method the total neutron densities in the system are divided into the Maxwellian part and the epi-thermal part. The latter has the distribution of $\left(1 / v^{2}\right) d v$ type with a graded diminution to zero, between velocties corresponding to energies of $5 k T_{n}$ and $k T_{n}$.

By assuming this type of the neutron spectrum, the ratio of total epi-thermal to Maxwellian part of neutron densities is given by the activity ratio of a foil, whose absorption cross section obeys $1 / v$ law below the cadmium cut-off velocity, by the following formulae :

$$
\beta^{\prime}=\frac{1}{Z W \frac{A_{\text {sub }}(0)}{A_{\text {ep } 1}(0)}-(1-Z)}
$$

where $\beta^{\prime}=$ the ratio of total epi-thermal to Maxwellian part of neutron densities, $Z=$ fraction of epi-thermal neutron density above cadmium cut-off, and

$$
W=\frac{v_{c}}{2 \sigma_{0} v_{0}} \int_{E_{c}}^{\infty} \sigma_{a}(E) \frac{d E}{E}
$$

where $v_{c}=$ cadmium cut-off velocity, $\sigma_{0}=$ absorption cross section for $2,200 \mathrm{~m} / \mathrm{sec}$ neutron, $v_{0}=2,200 \mathrm{~m} / \mathrm{sec}, \quad E_{\mathrm{c}}=$ cadmium cut-off energy and $\sigma_{a}(E)=$ absorption cross sections as a function of neutron energy.

For any neutron field whose energy spectrum can be fitted to Campbell's type the ratio of epi-thermal to thermal neutron densities may be determined by measuring cadmium ratio only and using $\mathrm{Eq}$. (9) through (11) with the appropriate value of $f_{\mathrm{ep} i}(x) /$ $f_{\text {sub }}(x)$ obtained by the experiment described in the next section.

\section{Experimental Procedures TO DETERMINE $f_{\text {epl }}(x) / f_{\text {sub }}(x)$}

Determination of the cadmium ratios (using $0.85 \mathrm{~mm}$ cadmium cover) was made for gold foils with thicknesses ranging from approximately $2 \mathrm{mg} / \mathrm{cm}^{2}$ to $80 \mathrm{mg} / \mathrm{cm}^{2}$. An experimental foil and two $40 \mathrm{mg} / \mathrm{cm}^{2}$ monitor foils were placed on a foil holder made of thin alminium plate and inserted into the glory hole of JRR-1. The experimental foil was placed just at the center of the core, No. 1. monitor foil $20 \mathrm{~cm}$ south of the center, and No.2, $40 \mathrm{~cm}$ north.

Core center of the reactor system was selected because of the following reasons :

(1) Low and position independent cadmium ratio

(2) Applicability of Campbell's type of neutron spectrum

(3) Local flatness of neutron distribution 
to the first order.

All the foils used were commercial, pure gold (purity $>99.99 \%$ ) in the form of discs of $1 \mathrm{~cm}$ in diameter and cadmium covers were square shape just fitted to contain the foils. The thickness of cadmium was determined by the considerations as follows :

(1) Almost perfect filtering $(X=0, F=1$ in Eq. (2))

(2) Independence of cut-off velocity on neutron spectrum.

Irraiation was made at the power level of $5 \mathrm{~W}$ for $5 \mathrm{~min}$. The experimental foils were irradiated with and without cadmium cover, and the irradiations were repeated at the same position in the core. Fluctuations of power level and the errors in irradiation time was checked by counting the activities of monitor foils and was estimated to be $\pm 3 \%$ even in the worst case.

Experimental foils were counted by $4 \pi$ gas flow G-M counter (RCL. Model 10202) several times and the specific activity of each foil was calculated. Monitor foils were counted by conventional end-window $\mathrm{G}-\mathrm{M}$ counter (Tracerlab. Type TGC-2).

\section{EXPERIMENTAL RESULTS}

Table 1 gives the activities with and without cadmium for a variety of foil thicknesses. All the activities are corrected to the moment of withdrawal time from the reactor and normalized for the irradiation of $5 \mathrm{~min}$ at $5 \mathrm{~W}$. Fig. 1 presents the specific activities and the cadmium ratios plotted as a function of the foil thickness.

Table 1 Cadmium ratios in JRR-1 core and foil thickness correction factors

\begin{tabular}{|c|c|c|c|c|}
\hline 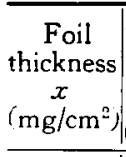 & $\begin{array}{c}\text { Bare foil } \\
\text { specific } \\
\text { activity } \\
A(x) \\
\text { (cpm/mg) }\end{array}$ & $\left|\begin{array}{c}\text { Cd covered } \\
\text { foil specific } \\
\text { activity } \\
A_{\mathrm{cd}}(x) \\
(\mathrm{cpm} / \mathrm{mg})\end{array}\right|$ & $\begin{array}{l}\text { Cadmium } \\
\text { ratio } \\
R_{\text {ed }}(x)\end{array}$ & $\begin{array}{c}\text { Foil } \\
\text { thickness } \\
\text { correction } \\
\text { factor } \\
f_{\text {epl }}(x) / f_{\text {sub }}(x) \\
\end{array}$ \\
\hline $0^{\dagger}$ & 3,480 & 2,180 & 1.60 & 1.000 \\
\hline 2.3 & 3,160 & 1,894 & 1.67 & 0.892 \\
\hline 10.0 & 2,513 & 1,338 & 1.88 & 0.679 \\
\hline 20.9 & 2,011 & 953 & 2.11 & 0.537 \\
\hline 30.7 & 1,713 & 775 & 2. 21 & 0.493 \\
\hline 40.1 & 1,498 & 632 & 2. 37 & 0.435 \\
\hline 52.2 & 1,300 & 515 & 2.52 & 0.391 \\
\hline 60.0 & 1,197 & 464 & 2.58 & 0.377 \\
\hline
\end{tabular}

\begin{tabular}{r|r|r|r|r}
66.4 & 1,112 & 420 & 2.65 & 0.362 \\
79.4 & 976 & 365 & 2.67 & 0.356 \\
85.2 & 911 & 335 & 2.72 & 0.347 \\
\hline
\end{tabular}

$\dagger$ All values for zero thickenss foil were determined by extra. poration.

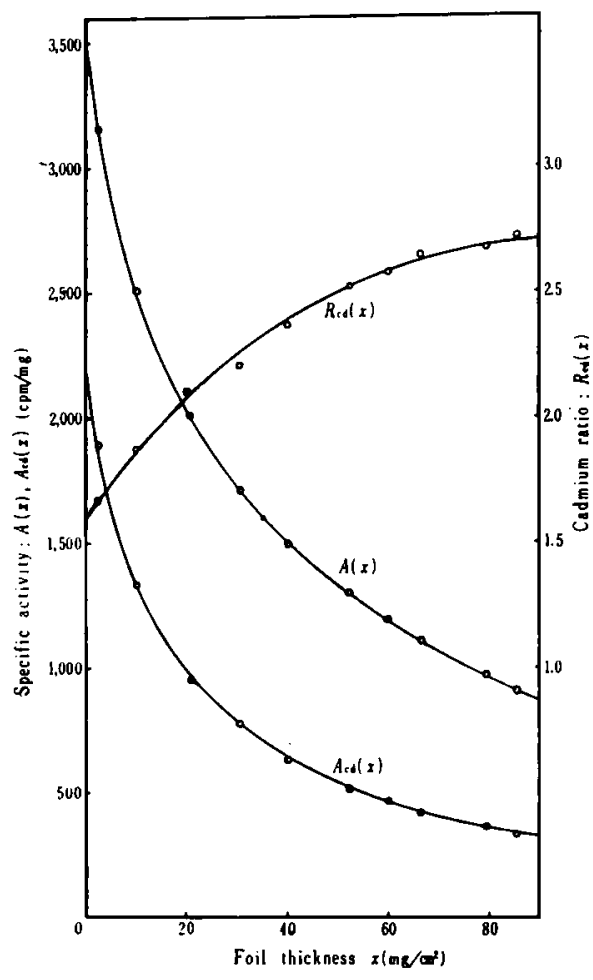

Fig. 1 Specific activities and cadmium ratios of gold foils irradiated at the center of JRR-1 core

For the purpose of separating the activities into the sub-Cd and the epi-Cd components, the cadmium filter was considered perfect with this value of thickness $(0.85$ $\mathrm{mm}$ ); i.e. $F=1$ and $X=0$ in Eq. (2). Fig. 2 is a graph of the variation of activity reduction with the foil thickness. The faster reduction of activity with the foil thickness is clearly observed in the case of epi-Cd activity than in that of sub-Cd one.

Dividing the $f_{\text {epl }}(x)$ by $f_{\text {sub }}(x)$ in Fig. 2 the foil thickness correction factor $f_{\text {epl }}(x) /$ $f_{\text {sub }}(x)$ was calculated as a function of thickness of gold. This function is tabulated in column 5 of Table 1 and presented graphically in Fig. 3. 


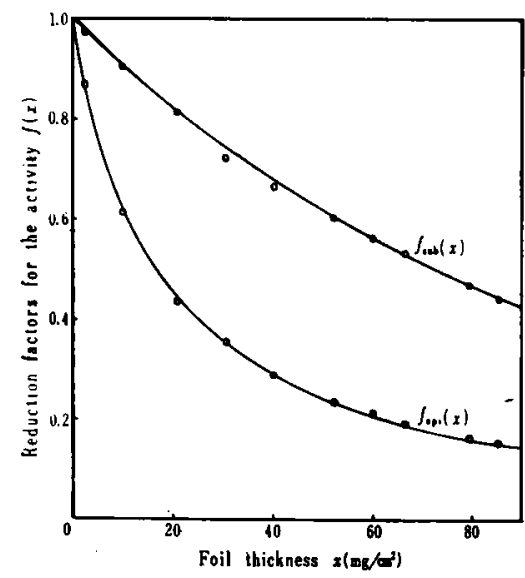

Fig. 2 Reduction factors for the sub-Cd and epi-Cd activities of gold foils measured by a $4 \pi$ beta counter

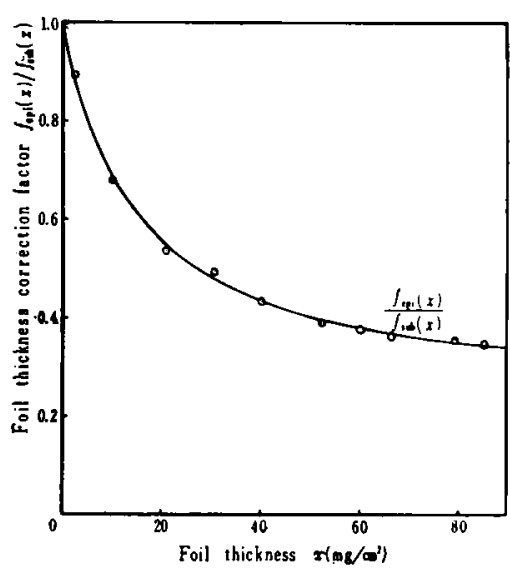

Fig. 3 Foil thickness correction factors for gold foils

The errors included in the curve of Fig. 3 are estimated as follows:

(1) Errors in irradiation $\leq 3 \%$

(2) Counting error $\leq 1.5 \%$

(3) Errors due to the ambiguity of extraporation $\leq 2 \%$

(4) Errors in separating the activities $\leq 12$ $\%$

Therefore, the total error involved would be approximately $4.5 \%$.

\section{INDEPENDENCE OF $\boldsymbol{f}_{\text {epl }}(\boldsymbol{x}) / f_{\text {sub }}(\boldsymbol{x})$ OF THE COUNTER OR OF THE FLUX RATIO}

The activity reduction factor $f(x)$ can be regarded as the product of three components.

$$
f(x)=f_{1}(x) \cdot f_{2}(x) \cdot f_{3}(x)
$$

where $f_{1}(x)$ means the reduction of neutron irradiation itself with the increase of foil thickness, $f_{\mathbf{2}}(x)$ means the beta activity selfabsorption in the foil and $f_{3}(x)$ is caused by the efficiency change with foil thickness for counting the liberated beta particles. $f_{3}(x)$ includes the effects of back-scattering and forward-scattering of beta particles as well as the intrinsic efficiency of the beta counter. So $f_{3}(x)$ makes the reduction factor dependent on the counting device whereas $f_{1}(x)$ and $f_{2}(x)$ do not. But when we make the ratio of $f_{\text {epl }}(x)$ to $f_{\text {sub }}(x), f_{3}(x)$ terms are approximately cancelled out by each other because the difference in distributions of the activated ${ }^{198} \mathrm{Au}$ nuclei in the foil will not play an important role in $f_{3}(x)$.

So far as the activities are measured by beta counting device, $f_{\text {epi }}(x) / f_{\text {sub }}(x)$ can be considered as counter independent and

$$
\frac{f_{\mathrm{epi}}(x)}{f_{\mathrm{sub}}(x)}=\frac{f_{1, \mathrm{epi}}(x) \cdot f_{2, \mathrm{epl}}(x)}{f_{1, \mathrm{sub}}(x) \cdot f_{2, \mathrm{sub}}(x)}
$$

$f_{1}(x)$ has two components; one is due to the flux depression near the foil, and the other the neutron self-shielding effect by the foil. The former can be taken as negligible compared with the latter. Neutron selfshielding effect by the foil can be considered independent of the flux ratio if we separate the effect into the one for the sub-Cd activity and for the epi-Cd activity. $f_{2}(x)$ is deeply concerned with the distribution of the activated nuclei in the foil, but is taken also independent of flux the ratio when the activity is properly separated.

In order to check the independence of $f_{\text {epl }}(x) / f_{\text {sub }}(x)$ of the counter or of the flux ratio two experiments were made of some cadmium ratios. One was made by counting the same foils that were used to determine $f_{\text {epl }}(x) / f_{\text {sub }}(x)$ in the former section by the conventional end-window G-Mcounter (Tracerlab. Type TGC-2). Table 2 presents the results of the measurements of cadmium ratio together with $A_{\text {sub }}(0) / A_{\text {epi }}(0)$ calculated by Eq. (9) using the value of $f_{\text {epi }}(x) / f_{\text {sub }}(x)$ in Fig. 3. The differences in $A_{\text {sub }}(0) / A_{\text {qpi }}(0)$ 
are within the limits of the experimental error except in the case of $2.3 \mathrm{mg} / \mathrm{cm}^{2}$ thickness. This exception might be caused by the difference of $f_{3}(x)$ in sub-Cd and in epiCd case since the forward scattering of beta particles plays some role in the range of this thickness.

Table 2 Results by end-window

\begin{tabular}{|c|c|c|}
\hline $\begin{array}{c}\text { Foil } \\
\text { thickness } \\
x \\
\left(\mathrm{mg} / \mathrm{cm}^{2}\right)\end{array}$ & $\begin{array}{c}\text { Cadmium } \\
\text { ratio } \\
R_{\text {cd }}(x)\end{array}$ & $\begin{array}{l}\text { Activity ratio } \\
\text { for ideal foil } \\
A_{\text {sub }}(0) / A_{\text {epi }}(0)\end{array}$ \\
\hline 2.3 & 1.72 & 0.64 \\
\hline 10.0 & 1.89 & 0.60 \\
\hline 20.9 & 2.11 & 0.60 \\
\hline 30.7 & 2. 30 & 0.61 \\
\hline 40.1 & 2.42 & 0.61 \\
\hline 52.3 & 2.51 & 0.59 \\
\hline 60.0 & 2.63 & 0.62 \\
\hline 66.4 & 2.62 & 0.60 \\
\hline 79.4 & 2.69 & 0.60 \\
\hline 85.1 & 2.71 & 0.60 \\
\hline
\end{tabular}

The second experiment was made by measuring the cadmium ratios of foils irradiated at the position of different flux ratio from the core center. The center of No. 2 experimental hole of JRR-I was selected for this purpose. This point is in graphite reflector $12 \mathrm{~cm}$ apart from the core edge, but Campbell's type of neutron spectrum is considered still available approximately there. The procedures of irradiation and counting are almost the same as those of the former experiment, and the results are presented in Table 3. The differences in $A_{\text {sub }}(0) / A_{\text {epi }}(0)$ are small enough except again in the case of $2.4 \mathrm{mg} /$ $\mathrm{cm}^{2}$ and the reason of the discrepancy may not be cleared this time.

Table 3 Results in No. 2 hole of JRR-1

\begin{tabular}{c|c|c}
\hline $\begin{array}{c}\text { Foil } \\
\text { thickness } \\
x\end{array}$ & $\begin{array}{c}\text { Cadmium } \\
\text { ratio } \\
R_{\mathbf{c d}}(x)\end{array}$ & $\begin{array}{c}\text { Activity ratio } \\
\text { for ideal foil } \\
A_{\text {sub }}(0) / A_{\text {epi }}(0)\end{array}$ \\
\hline 2.4 & 2.20 & 1.05 \\
10.3 & 2.51 & 1.01 \\
47.4 & 3.41 & 0.98 \\
79.4 & 3.80 & 0.99 \\
\hline
\end{tabular}

From the above two experiments the independence of $f_{\mathrm{epl}}(x) / f_{\mathrm{sub}}(x)$ of the counter or of the flux ratio is testified though some suspicions remained in the thinnest case.

\section{CONSIDERATIONS ON THE COMPONENTS OF ACTIVITY REDUCTION FACTOR}

As is pointed out in the former section, important components of the activity reduction factor are neutron self-shielding factor $f_{1}(x)$ and beta self-absorption factor $f_{2}(x) . f_{3}(x)$ is not of importance, especially when $4 \pi$ counter is used as a activity counting device.

It is interesting to separate the experimentally determined $f(x)$ into $f_{1}(x)$ and $f_{2}$ $(x)$. For this purpose another set of gold foils with cadmium covers was irradiated again at the core center of JRR-1. In this case power level for irradiation was increased to $50 \mathrm{~W}$. The disintegration rates of irradiated foils were determined by beta-gamma coincidence counting which is a standard technique, so the detailed procedures will not be reproduced here. We only mention that the counters used are a beta scintillation counter with a stilbene crystal and a gamma one with $\mathrm{NaI}$ crystal.

Specific disintegration rates of the foils thus determined are proportional to epi-Cd neutron self-shielding factor $f_{1, \text { epl }}(x)$ and are plotted in Fig. 4.

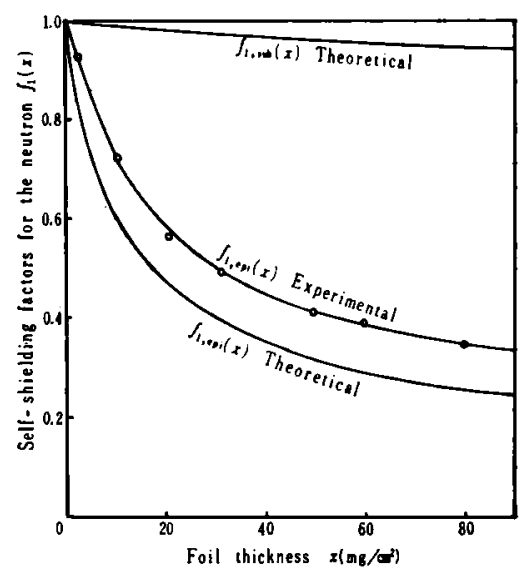

Fig. 4 Self-shielding factors for the sub-Cd and epi-Cd neutrons by gold foils 
Self-shielding effect for sub-Cd neutrons is much less because the neutron absorption cross section of gold has smaller value in sub-Cd than in resonance region. So, as for $f_{1, \text { sub }}(x)$ we did the estimation by the calculation as follows :

$$
f_{1, \mathrm{sub}}(x) \frac{1}{2 \mu d}\left\{1-e^{-\mu d}(1-\mu d)+\mu^{2} d^{2} E_{\mathrm{s}}(-\mu d)\right\}
$$

where $\mu=$ average absorption coefficient of sub-Cd neutrons in gold and $d=$ foil thickness. $f_{1, \text { sub }}(x)$ thus determined is also plotted in Fig. 4.

Gross reduction factors $f(x)$ in Fig. 2 are the products of $f_{1}(x)$ and $f_{2}(x)$ since the activities were counted by $4 \pi$ counter in this case. So, by dividing $f(x)$ 's in Fig. 2 by $f_{1}(x)$ 's in Fig. 4. beta self-absorption factors in gold foils $f_{2}(x)$ 's can be extracted and are shown in Fig. 5. Strictly speaking, $f_{2}(x)$ thus determined includes the small contribntion from gamma activity of foils, but it may be adopted as the beta self-absorption factor for the practical use.

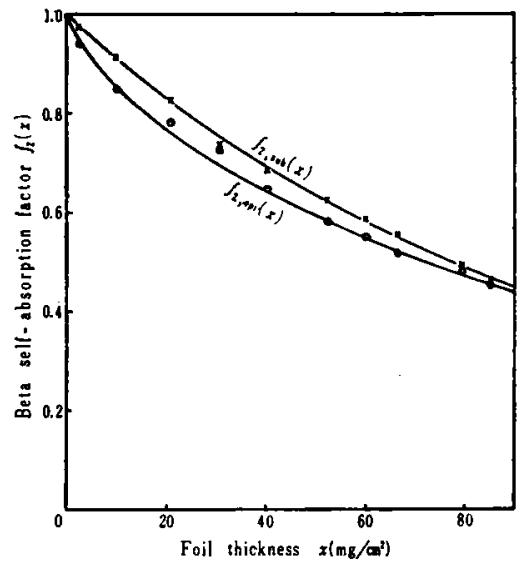

Fig. 5 Beta self-absorption factors for the sub-Cd and epi-Cd activities in gold foils

Three remarkable condusions are obtained from Figs. 4 and 5.

(1) Self-shielding factor for epi-Cd neutrons shows substantial difference from the prediction of theory. Theoretical curve presented in Fig. 4 is based on the local constancy of neutron spectrum distribution near the single resonance of BreitWigner type and is calculated by the formula ${ }^{(3)}$

$$
f_{1, \mathrm{epl}}(x)=\frac{\int_{-\infty}^{\infty} d \xi \int_{0}^{1}\left(1-e^{-\frac{\sigma_{a} \cdot x}{\mu}}\right) \mu d \mu}{\int_{-\infty}^{\infty} \sigma_{a} x d \xi}
$$

with $\sigma_{a}=\frac{\sigma_{a 0}}{1+\xi^{2}}$

where $\sigma_{a 0}=$ absorption cross section at resonance peak, and $x=$ foil thickness.

This theoretical curve shifts upwards a little when the Doppler broadening of the resonance peak is taken into account, but the large deviation from the experi. mental results can not be explained.

(2) Beta self-absorption factors for sub$\mathrm{Cd}$ and epi-Cd activities show the two different curves as are seen in Fig. 5, but the difference between the two curves might be regarded smaller than expected from the fact that the two kinds of activities have quite different distributions in the foil.

(3) Since there is not so much difference between $f_{2, \text { epl }}(x)$ and $f_{2, \text { sub }}(x)$, and $f_{1}$, $\operatorname{sub}(x)$ reads approximately one througthout the region, foil thickness correction factor $f_{\text {epl }}(x) / f_{\text {sub }}(x)$ may be roughly approximated by $f_{1, \text { epi }}(x)$. One can observe this fact from the similarity of the $f_{\text {epl }}(x) / f_{\text {sub }}(x)$ curve in Fig. 3 and the $f_{1, \mathrm{epl}}(x)$ curve in Fig. 4.

\section{EPI-THERmal NeUtron DeN- SITY AND AVERAGE THERMAL NEUTRON LIFE TIME IN JRR-1 CORE}

From the mesurements described in Sec. II, we obtained the activity ratio of gold foil in JRR-1 core as

$$
\frac{A_{\text {sub }}(0)}{A_{\text {epi }}(0)}=0.596 \text {. }
$$

Assuming the value of $\mu$ in Campbell's nomenclature as $4.2^{*}$ and cadmium cut-off energy as $0.5 \mathrm{eV}, Z$ in Eq. (10) is derived as $Z=0.47$.

\footnotetext{
* $\mu$ is concerned with the effective low energy end of the epi-thermal distribution. 4.2 is estimated from the experimental results by Poole on the light water moderated system quoted in reference (2).
} 
Further, assuming the following values

$$
\begin{aligned}
& \int_{E_{c}}^{\infty} \sigma_{a}(E) \frac{d E}{E}=1.534 \text { barns* }^{*} \\
& \sigma_{0}=98.8 \text { barns }
\end{aligned}
$$

the ratio of total epi-thermal to Maxwellian part of neutron densities in JRR-1 core can be calculated using Eq. (10) and has a value of 0.11 . This ratio may be transformed to the flux ratio $\phi_{\text {epi }} / \phi_{M}=0.10$ with the same assumption on $\mu$, where $\phi_{\mathrm{epi}}$ means the epithermal neutron flux in one logarithmic energy interval and $\phi_{s}$ is the Maxwellian part of the neutron flux.

We do not insist that the neutron spectrum in JRR.1 core has the immutable character represented by the above ratios, but only would mention that the activity ratio of gold foils may be consistently interpreted with the use of the parameters estimated above but this depends on the asummed spectrum. It is an inevitable result of the integral mesurement that it can not give a definite answer but the adequacy of the result depends entirely on the validity of spectrum type assumed.

Next we can make some considerations on the average thermal neutron life time in JRR-1 core. Equating the neutron slowing down density at $E^{*}$ with the total neutron absorption rate below $E^{*}$ and assuming the relation

$$
q\left(E^{*}\right)=\xi \Sigma, \phi_{\text {epi }}
$$

the following equation results for $1 / v$ absorbing medium

$$
l=\frac{\sqrt{\pi}}{2 v_{0} \xi \Sigma} \sqrt{\frac{E_{0}}{E_{n}}}\left[\frac{\phi_{\mathbb{N}}}{\phi_{\mathrm{epl}}}+\frac{4}{\sqrt{\pi \mu}}-\sqrt{\frac{16 E_{n}}{\pi E^{*}}}\right]
$$

where $l=$ average thermal neutron life time in the case of an infinite medium, $v_{0}=2,200 \mathrm{~m} /$ sec, $\xi \Sigma_{s}=$ slowing down power of the medium, $E_{0}=$ energy corresponding to the neutron velocity of $2,200 \mathrm{~m} / \mathrm{sec}, E_{n}=$ energy corresponding to the neutron temperature, $\mu=$ fictitious low energy end of epi-thermal neutron distribution defined by Campbell, and $E^{*}=$ energy point in epi-thermal region where the flux ratio $\phi_{x} / \phi_{\text {ept }}$ is measured $(=4.9 \mathrm{eV}$ in the case of gold), Adopting the value of $\phi_{\mathrm{ep}} / \phi_{\mathrm{s}}=0.10$ mentioned above and using the plausible values for other factors about 34 $\mu_{\mathrm{sec}}$ was obtained for the average thermal neutron life time in JRR-1 core. This value is comparable with that of about $41 \mu \mathrm{sec}$ computed by

$$
e=\frac{1}{\Sigma_{a} v}
$$

for the JRR-1 core solution but is remarkablly different from the value of about $140 \mu_{\mathrm{sec}}$ resulted by the kinetical experiments for JRR $-1^{(5)}$. This discrepancy may be explained by estimating the effect of a reflector on the reactor kinetics.

(Received June 4, 1960)

\section{- REFERENCES- -}

(1) M. A. GReENField, et al. : Nucl. Sci. Engng., 2. 246 252 (1957).

(2) C. G. CAMPBell, et al. : 2nd Geneva Conf., $\mathrm{P} / 10$ (1958).

(3) G. E. Hansen, W. H. Roach : Proc. Brookhaven Conf., (BNL-433), 13 25 (1956).

(4) K. Jirlow, E. Johansson: Reactor Science, 11, 101 107 (1960).

(5) K. SUMITA, et al. (JAERI) : Unpublished.

\section{金箔による熱外中性子密度の測定}

\section{古橋 晃, 松本圭司，大部 誠}

原子师体系における中性子のエネルギー分布を測定 する手段の一つとして，いわゆる共鳴䇴のカドミウム 比によって熱外領域の中性子束の大きさを知ろ 5 とす る方法がひろく用いられる。このとき通常用いられる 程度の厚さの萡では，中性子に対する箔の自己遮蔽效 果や $\beta$ 放射能の䇴内自己吸収勃果が相当きいてくるの でカドミウム此が䇴の厚さによっていちじるしく変 化し，䇴の厚さを指定しなければカドミウム比の意味

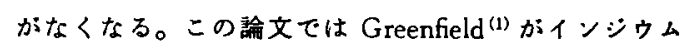
萡について行なったと同梾の方法で，金䈃の場合につ いて，有限な厚さの䇴での㴬定值を厚さ0の理想箔で の值に換算するための補正係数を決定した結果扩よび その保数の物理的な内容に関する若干の考察を記し た。また JRR-1 炻心内での測定の結果, 全熱外中性 子密度とマクスウェル部分の中性子密度との比として 0.11 とい5值を得た。

* Estimated by adding the $1 / v$ contribution to the experimental result on resonance absorption of gold by Jirlow ${ }^{(4)}$. 